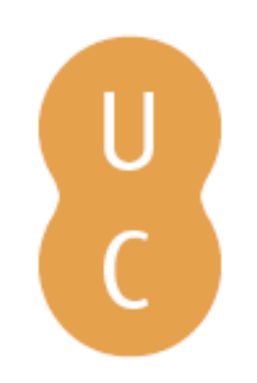

\title{
nommalina
}

\section{"Falta alguém em Nuremberg": charges comunistas sobre a violência do Estado Novo (1937-1945)}

\author{
Autor(es): $\quad$ Tavares, Rodrigo R.
}

Publicado por: Imprensa da Universidade de Coimbra

URL

persistente: URI:http://hdl.handle.net/10316.2/39001

DOI: $\quad$ DOI:http://dx.doi.org/10.14195/978-989-26-1064-1_7

Accessed : $\quad$ 26-Apr-2023 13:22:14

A navegação consulta e descarregamento dos títulos inseridos nas Bibliotecas Digitais UC Digitalis, UC Pombalina e UC Impactum, pressupõem a aceitação plena e sem reservas dos Termos e Condições de Uso destas Bibliotecas Digitais, disponíveis em https://digitalis.uc.pt/pt-pt/termos.

Conforme exposto nos referidos Termos e Condições de Uso, o descarregamento de títulos de acesso restrito requer uma licença válida de autorização devendo o utilizador aceder ao(s) documento(s) a partir de um endereço de IP da instituição detentora da supramencionada licença.

Ao utilizador é apenas permitido o descarregamento para uso pessoal, pelo que o emprego do(s) título(s) descarregado(s) para outro fim, designadamente comercial, carece de autorização do respetivo autor ou editor da obra.

Na medida em que todas as obras da UC Digitalis se encontram protegidas pelo Código do Direito de Autor e Direitos Conexos e demais legislação aplicável, toda a cópia, parcial ou total, deste documento, nos casos em que é legalmente admitida, deverá conter ou fazer-se acompanhar por este aviso.

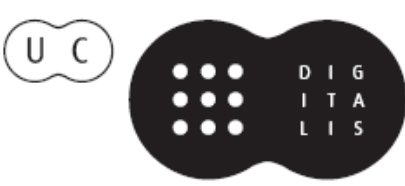


A L B ERTO PENA-RODR ÍGUEZ HELOISA PAULO

COOR D.

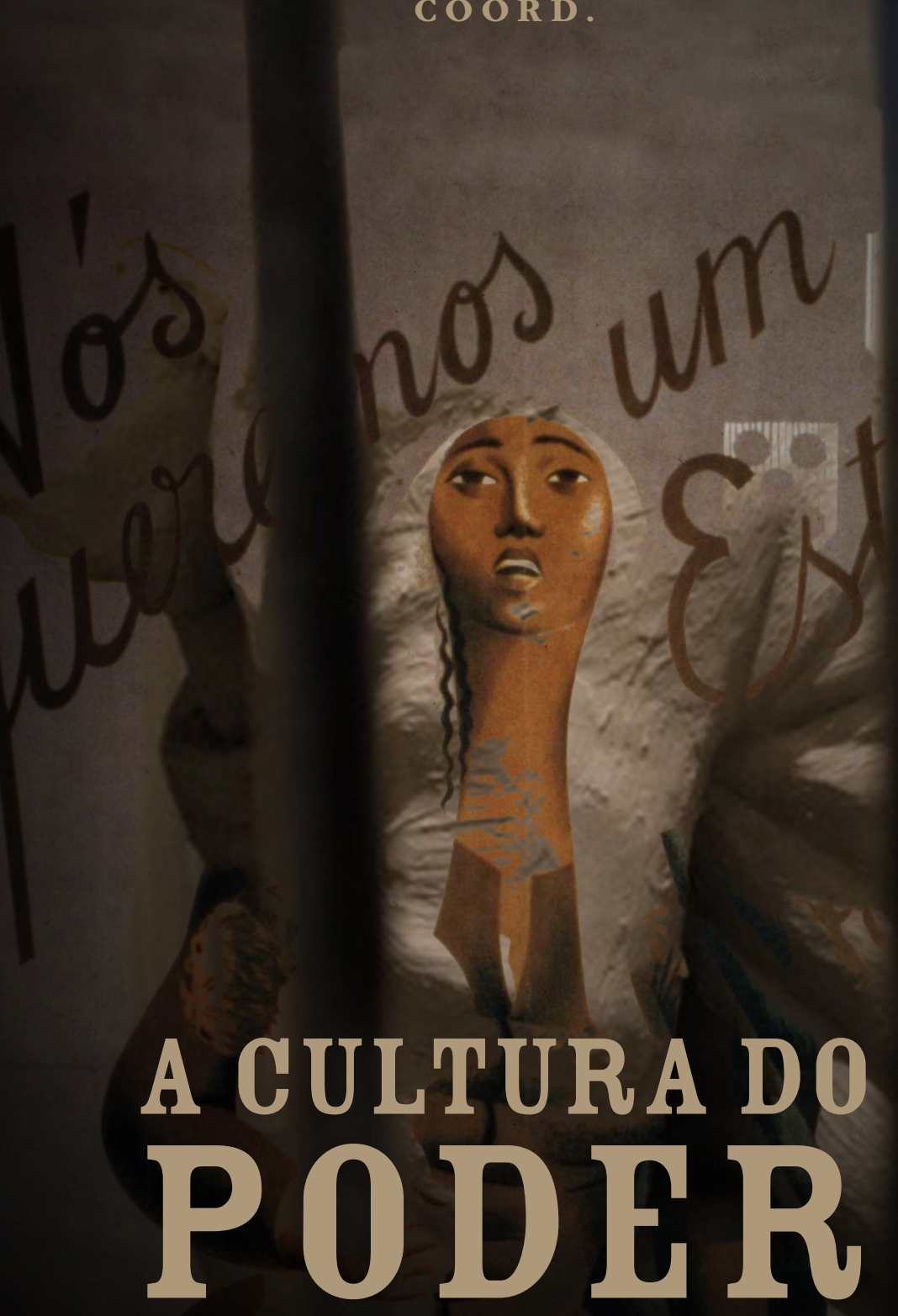

A PROPAGANDA INOS ESTADOS AUTORITÁRIOS 


\section{“FALTA ALGUÉm EM NUREMBERG”: CHARGES COMUNISTAS SOBRE A VIOLENCIA DO ESTADO NOVO (1937-1945)}

"[...] li num livro de Pierre Vidal-Naquet a frase sobre a tortura que me parece justíssima 'tortura começa como um método de interrogatório, desenvolve-se como um método de opressão e finalmente se transforma num Estado clandestino, que corrói as próprias raízes da vida de uma nação'”

Memórias. Gregório de Bezerra

A propaganda do Estado Novo utilizou o rádio, o cinema, as artes plásticas e variados impressos para defender a visão do regime como representante dos anseios nacionais, de maneira una e indivisível. Getúlio Vargas aparece como o líder inconteste da pátria, sua expressão mais elevada e acabada. Embora longe da eficácia e da abrangência utilizada pelos regimes nazifascistas, a propaganda varguista, aliada à censura e à repressão, foi importante para configurar uma visão sobre o período e seu chefe. O brasileiro lia, ouvia e via um líder popular que supostamente representava seus interesses ${ }^{1}$.

${ }^{1}$ Para uma análise sobre a propaganda e a ideologia varguista: LENHARO, Alcir. Sacralização da política, Campinas: Papirus, 1986 e CAPELATO, Maria Helena. Multidões em cena: propaganda política no varguismo e no Peronismo, São Paulo: Papirus, 1998 
Esse discurso oficial, ainda que filtrado pelo olhar da população, encobria a resistência ao mesmo, a ação que ocorria nas sobras, e a própria violência do regime. Nesse contexto, o conjunto de desenhos ${ }^{2}$ "Falta alguém em Nuremberg", sobre a tortura ocorrida entre 19371945, publicado nos jornais comunistas entre 1945-1947, realçava um tema incômodo e se contrapunha à memória oficial do Estado Novo. Todavia, a série de imagens denunciadoras constrói sentidos ligados aos interesses e contradições dos próprios comunistas no período.

O Partido Comunista Brasileiro, fundado em 1922, conhece sua maior expansão no período compreendido entre o fim da Segunda Guerra Mundial e a ilegalidade da legenda em 1947. Após o fim da era ditatorial do Estado Novo (1937-1945) e com a vitória contra os regimes autoritários do nazifascismo ao lado da URSS, o clima político era favorável a uma simpatia pelo PCB. Para um partido acostumado às agruras da repressão, à pequena influência sindical e política, esse período de legalidade e crescimento é atípico. O aumento do número de militantes é vertiginoso, também é formada pela primeira vez uma bancada de políticos eleitos ${ }^{3}$ e o crescimento da sua imprensa acontece nos principais estados do país. A legenda passa a ter uma visibilidade impar e a influir de maneira importante no contexto político nacional.

O militante comunista e historiador Moisés Vinha comenta o clima da época:

É compreensível a expectativa que então cerca o PCB, e não apenas por parte de seus amigos e simpatizantes. No ambiente

\footnotetext{
2 Para uma análise sobre a iconografia comunista. TAVARES; Rodrigo. Desenhando a Revolução: a luta de imagens na imprensa comunista (1922 -1964), Tese de Doutorado, USP, 2010.

3 Uma primeira tentativa, longe de ter a mesma influência, foi a do Bloco Operário e Camponês na década de 1920. KAREPOVS, Dainis. A classe operária vai ao parlamento: o Bloco Operário e Camponês do Brasil (1924 -1930), São Paulo: Alameda, 2006.
} 
de euforia e esperanças do pós-guerra, de oxigenação da atmosfera política do país pela vigência das liberdades democráticas, o PCB aparecia aos olhos de muitos como a única coisa realmente nova, desconhecida, prenhe de promessas e não comprometida com o status quo anterior. Seu principal líder é um jovem de grande prestígio entre a massa, cercado pela auréola de heroísmo; beneficia-se da simpatia que então cerca a União Soviética, a grande vitoriosa na guerra contra o nazismo. Além disso, sua política não é sectária nem exclusivista e seus métodos são inovadores em relação aos hábitos brasileiros. O Partido abre suas portas para quem aceitar seu programa e acatar a sua disciplina. ${ }^{4}$

Uma aspecto interessante a ser levado em consideração nesse novo contexto é, justamente, como lidar com o passado recente, com o Estado Novo. A história sempre é objeto de disputa entre diversos grupos que pretendem definir sua visão sobre ela de acordo com seus interesses. Sindicatos, estados, religiões e partidos vigiam o passado, a história5. Com o regime posto abaixo, não faltavam candidatos a coveiros do Estado Novo, elencando sua atuação contra o regime. Nesse sentido, é importante destacar quem "começou" a luta: parte da elite oligárquica usou como prova da sua oposição a Getúlio Vargas o manifesto dos mineiros de $1943^{6}$, mas também

\footnotetext{
${ }^{4}$ VINHAS, M. O partidão: a luta por um partido de massas, 1922-1974. São Paulo: HUCITEC, 1982, p. 87

5 A relação da história com o poder e a dos comunistas com o seu passado foi analisada, respectivamente, por: FERRO, Marc. A história vigiada., São Paulo, Martins Fontes, 1987 e PANDOLFI, Dulce. Camaradas e Companheiros: Memória e História do PCB. Rio de Janeiro: Relume Dumara, 1995.

${ }^{6}$ Segundo Edgard Carone, "Podemos afirmar que quem inicia [a luta] são os comunistas, em fins de 1941; no ano seguinte, temos a presença de facções socialistas, que aparecem com objetivos programáticos próprios, mas sem terem ligação com o passado; ou é a vez de corrente do Exército, ligada ao tenentismo e ao positivismo. Em 1943, facção da oligarquia oposicionista anuncia sua posição através do Manifesto dos Mineiros, episódio que é posterior à ação individual de vários membros de sua classe, que a partir de 1942 agem no meio estudantil: dessa maneira, as facções mais
} 
socialistas, militares e estudantes marcavam suas ações de resistência ao regime. O PCB, o principal alvo da repressão acirrada a partir da insurreição comunista de 1935, mas praticamente ininterrupta durante sua existência, também tinha questões delicadas a tratar na sua reconstrução do passado.

Por um lado, os militantes viveram um período ininterrupto de clandestinidade, repressão e, quando presos, a tortura física e psicológica era largamente utilizada. Essa resistência cotidiana durante o Estado Novo tem uma importância fundamental no que se refere à visão que os militantes da base do partido tinham do período. O militante Deoclécio Santana, durante a vigência do regime de exceção, mas já no seu ocaso, afirma:

...o dever nos indica que devemos continuar unidos e mobilizados...lutando por uma saída pacífica dos tenebrosos anos durante os quais ficamos submetidos contra vontade...Compreendemos que não é este o momento para ódios e ressentimentos porque nos achamos acima desses baixos sentimentos e porque a causa assim exige. Mas na nossa memória dificilmente poderão apagar-se os vexames e as perseguições que nos fizeram, somente por desejarmos a nossa sindicalização, visto que todos somos descontados em nosso pequeno salário, para o sindicato, sem entanto podermos pertencer a ele, tanto que muitos companheiros foram fichados na polícia só por denunciar os erros, e procurar os seus direitos.... ${ }^{7}$

dinâmicas da classe entram tarde na batalha do Estado Novo, apesar de quererem nos fazer crer que o Estado Novo ruiu por sua causa (grifo nosso)" CARONE, Edgard. Brasil anos de crise 1930-1945, São Paulo: Ática, 1991, pp. 311-312.

7 Manifesto. Comitê Democrático dos Operários Ensacadores de Café de Santos. Jornal A Tribuna, Santos, 6 abr., 1945. 
Para esse grupo, a identidade de comunista ${ }^{8}$ foi formada por essa resistência cotidiana, nas sombras, por essas agruras, pelas sevícias nos porões da polícia ${ }^{9}$, o que alçava o partido ao grande personagem da resistência ao Estado Novo ${ }^{10}$.

Por outro lado, duas políticas adotadas pela legenda colocavam os comunistas numa situação ambígua em relação ao Estado Novo e Getúlio Vargas: o partido apoiou ${ }^{11}$ o ditador após a entrada do Brasil na Segunda Guerra do lado dos aliados e teve influência no chamado queremismo, o movimento pela elaboração de uma constituinte sob a presidência varguista.

Nesse contexto ambíguo, os jornais Hoje, de São Paulo, e o Tribuna Popular, do Rio de Janeiro, publicaram uma série de desenhos sobre a tortura no Estado Novo, que passa a ser intitulada "Falta alguém em Nuremberg". O título da série de desenhos fazia

8 “A geração de esquerda que emergirá entre 1943 e 19467 irá reconhecer seu passado não nas precaríssimas batalhas dos anos 20, mas no episódio de 35 , na Guerra da Espanha, na residência de Stalingrado e no combate ao Estado Novo". BRANDÃO, Gildo. A esquerda positiva: as duas almas do Partido Comunista - 1920/1964, São Paulo: Hucitec, p. 154

9 A própria prisão é um local importante da ação e identidade comunista. São famosos os coletivos comunistas que organizavam as prisões e contribuíam com a elevação cultural dos presos. Ainda que com uma visão um pouco idílica, Carone parece tocar num ponto importante quando afirma que "a razão de estar na prisão, para o militante, é contingência do seu ideal. A prisão é continuidade de seu ideal, ao mesmo tempo, afirmação de seu ideal. A prisão é continuidade de sua militância, onde ele continua a afirmar os seus princípios, a ter maior certeza de seu objetivo". CARONE, Edgard. Brasil anos de crise 1930-1945, São Paulo: Ática, 1991, p. 269.

$10 \mathrm{O}$ ápice da glorificação da ação dos militantes contra o Estado Novo ocorre com a publicação da trilogia Subterrâneos da Liberdade, que busca justamente mostrar a ação da oposição a ditadura varguista. Sob os ditames do realismo socialista, Jorge Amado constrói uma história francamente exagerada da ação dos comunista. O sinal mais evidente é a mudança de data de um boicote ao embarque de mercadorias no porto de Santos/SP para a Espanha franquista. A greve ocorreu em 1946, mas Amado a situa no Estado Novo para provar a ação comunista.

11 Destroçado pela repressão posterior insurreição comunista de 1935, O PCB conviveu com grupos desarticulados de comunistas que possuíam visões diferentes sobre o processo político. Todavia o ponto de vista vitorioso optou pelo apoio ao ditador. 
referência à série de reportagens publicadas pelo influente jornalista David Nasser na popular revista O Cruzeiro.

Nasser publica a primeira matéria em 26 de outubro de 1946 e depois volta a publicar mais cinco reportagens entre janeiro e fevereiro de $1947^{12}$. O conjunto, acrescido de material inédito, foi transformado em livro pela Edições Cruzeiro em 1947, ganhando várias reedições. No livro, Nasser detalha as torturas:

Os policiais brasileiros esmagavam testículos com uma espécie de alicates, a que chamavam pelo diminutivo de 'anjinho' corruptela de Higino, nome do escrevente da Polícia que os inventou (...). Os policiais brasileiros do Sr. Getúlio Vargas enfiavam arames nos ouvidos dos presos (...) enfiavam arames na uretra dos presos e, com um maçarico, aqueciam esses arames até ficarem em brasa (...) apertavam o crânio dos presos até que eles morressem ou enlouquecessem ${ }^{13}$

O detalhamento dos requintes de crueldade, evidentemente, buscava desmoralizar o regime passado. Contrapunha o horror das masmorras à ufanista propaganda de Vargas. O jornalista comenta ainda a atitude de resistência dos presos:

Os primeiros detidos sofrem torturas espantosas. Uns resistem heroicamente aos apertos dos testículos, aos maçaricos nas nádegas e na sola dos pés e às duras pancadas nas costas e nos rins (...). Se o preso surrado, martirizado, ensangüentado, sem unhas, ainda resistia, eles mandavam buscar a esposa ou a filha e, na presença do homem resistente ela era espancada. Se ele ainda

\footnotetext{
12 CARVAlHO, Luiz. Cobras Criadas: David Nasser e o Cruzeiro, São Paulo: Senac, 2001, p. 179.

13 NASSER, David (4. ${ }^{a}$ ed.). Falta alguém em Nuremberg, Rio de Janeiro: Edições O Cruzeiro, 1966, p. 5.
} 
se mantivesse firme, a mulher era posta nua, e em sua vagina os miseráveis introduziam buchas de mostarda. ${ }^{14}$

O eixo da série de reportagens e do livro posterior é a comparação entre o tratamento dado aos criminosos de guerra nazistas, julgados na cidade de Nuremberg, e os agentes brasileiros. Segundo Nasser, no prefácio da primeira edição da obra "As atrocidades praticadas no Brasil pela polícia política do Capitão Filinto Strubling Müller excederam, em alguns pontos, as torturas infligidas pela Gestapo aos judeus, antinazistas e prisioneiros aliados." E a conclusão é precisa: "Observarão os senhores, apenas, que, enquanto os nazistas alemães pagaram ou estão em vias de pagar seus crimes espantosos, os policiais brasileiros, autores de crimes contra a humanidade, mantem-se em seus postos, impunes e felizes, quase todos bem instalados na vida" 15 .

Embora denuncie os policiais e o chefe de polícia Filinto Muller, a tônica da obra é buscar julgar o principal autor desses bárbaros crimes como havia sido feito com os nazistas em Nuremberg. E para Nasser:

(...) o primeiro grande culpado, a seu ver, é o Sr. Getúlio Vargas, que poderá fugir a todos os julgamentos atuais, mas não escapará ao implacável, justo e sereno veredito da História. Logo que os fatos se coloquem dentro da perspectiva de análise, ele será apontado no Brasil como o maior assassino dentre os assassinos que viveram no tempo de sua vida. ${ }^{16}$

\footnotetext{
14 Ibidem, p. 53.

15 Ibidem, p. 5.

16 Ibidem, p. 6.
} 
Ou seja, para Nasser, Getúlio Vargas era o responsável pelas sevicias abomináveis descritas em detalhes no livro e na série de reportagens e merecia ser julgado por esses crimes, da mesma maneira que os nazistas foram julgados pelos seus. Enquanto a propaganda varguista realçava o papel do Brasil na derrota dos regimes nazifascistas, seja pela mobilização popular na "front interno" ou pela ação da Frente Expedicionária Brasileira no "front externo", Nasser equiparava os crimes de Vargas àqueles do Eixo.

Getúlio Vargas esperava um julgamento diferente. Em outubro de 1945, afirmou que "A História e o tempo falarão por mim, discriminando responsabilidades" 17 Todavia o jornalista queria um outro desfecho. Nasser afirma ser "impossível a Getúlio Vargas negar sua culpabilidade no assassínio e tortura dos presos políticos durante o longo período que durou a noite fascista" 18 Evidentemente, o periodista estava ciente de que os defensores do presidente poderiam argumentar que ele desconhecia o que ocorria nas delegacias e não poderia ser responsabilizado por eventuais ações individuais e exageros. Nesse sentido, é importante aproximar ao máximo Vargas de casos concretos.

Ao citar o substituto de Felinto Muller na policia, afirma que:

[O Coronel Alcides] Etchegoyen fez vários relatórios ao Sr. Getúlio Vargas. Contou as espantosas atrocidades praticadas por um grupo de homens do ex-chefe de polícia. As tremendas desonestidades, os desvio das verbas secretas. Jamais o $\mathrm{Sr}$, Getúlio Vargas tomou qualquer atitude no sentido de definir responsabilidades, porque, entre os responsáveis maiores, estava

17 Apud TUCCI CARNEIRO, Maria. (2. ${ }^{\text {a }}$ ed.) Anti-semitismo na era Vargas: fantasmas de uma geração (1930 -1945), São Paulo: Brasiliense, 1995, p. 1.

18 Ibidem, p. 102. 
ele próprio, que dera seu beneplácito a esse método científico de morte lenta. ${ }^{19}$

Portanto, não poderia "negar" conhecimento sobre as atrocidades de Felinto. Ademais, afirma que Getúlio Vargas contratou para sua guarda pessoal policial processado e demitido que usava "maçarico" para torturar os presos 20

Amilcar Dutra Menezes, ex-diretor do Departamento de Imprensa e Propaganda (DIP), atribuía as críticas de Nasser a uma suposta negativa de Getúlio Vargas em conceder uma entrevista exclusiva. Seja qual for o estopim, o fato é que Nasser descreve as torturas em detalhes e aponta o presidente como o principal responsável. Ademais, também reconstrói sua biografia durante o Estado Novo: surpreendentemente, "revela" que "ele e [o fotógrafo Jean] Mazon estiveram sob a cerrada marcação do DIP" ou, nas palavras de Nasser, "do tremendo círculo de ferro que esmagava nossas produções jornalísticas”. ${ }^{21}$

David Nasser e Jean Mazon formaram uma dupla importante na revista Cruzeiro, modernizando, em diversas fotorreportagens, o jornalismo impresso no país. Essas publicações muitas vezes serviram de vitrine para realizações modernizantes do Estado varguista. Embora Assis Chateaubriand, o proprietário da revista, fosse adepto do liberalismo e do americanismo, o seu anticomunismo o aproximavava dos conservadores e do ditador em muitas posições. ${ }^{22}$

19 Ibidem, p.29.

20 Ibidem, p.63. Lira Neto retoma a informação que Getúlio Vargas impediu o fuzilamento dos líderes da insurreição comunista, mas "não impediu a instituição da tortura como método investigativo... nenhuma denúncia de violência (...) foi devidamente apurada”. NETO, Lira. Getúlio: do governo provisório à ditadura do Estado Novo (1930 -1945), São Paulo: Cia. Das Letras, 2013, p. 259.

21 CARVALHO, Luiz. Cobras Criadas: David Nasser e o Cruzeiro, São Paulo: Senac, 2001, p. 181.

22 COSTA, Helouise. "Entre o local e o global: a invenção da revista O Cruzeiro in. COSTA, Helouise \& BURGI, Sergio. As origens do fotojornalismo no Brasil: um olhar sobre O Cruzeiro 1940/1960, São Paulo: Instituto Moreira Salles, 2012, p. 25. 
Tendo em vista que o PCB utiliza do mesmo título do jornalista do O Cruzeiro, é interessante analisar a visão comunista sobre o Estado Novo nesse período de legalidade. A publicação da série de desenhos "Falta alguém em Nuremberg" tinha o caráter de denúncia, uma vez que, sob forte censura, o grosso da população não teve conhecimento sobre as arbitrariedades praticadas pelo regime. Interessante notar como o partido mostra a face violenta do Estado Novo, e quais são os personagens envolvidos nessa representação iconográfica.

O primeiro desenho localizado sobre a tortura foi publicado no Tribuna Popular de 16 de setembro de 1945 na matéria "Agentes da gestapo no Brasil". O texto denuncia acordo secreto da polícia do Rio com o regime nazista. A data é importante pois ocorre ainda na vigência do Estado Novo e antes da publicação da série de Nasser.

O desenho de Paulo Werneck mostra um preso nu, deitado no chão e com as mãos para trás enquanto dois torturadores estão em pé e com o chicote na mão. As braçadeiras com o símbolo do sigma e da suástica mostram a aliança entre os nazistas e os integralistas. Caracterizado dessa maneira, o leitor vê agentes da gestapo e integralistas comandando a tortura no Estado Novo sob a liderança, segundo o texto, do chefe de polícia Filinto Muller. A aproximação entre as duas ideologias ocorre também pela representação muito similar dos personagens, claramente inspirados em Hitler, com seu cabelo de lado e bigode característicos.

Os integralistas tinham grande penetração no governo Vargas, mas, após o punch de 1938, muitos terminaram na cadeia ou no exílio. Ainda assim, colocar ambos os personagens como torturadores aproximava o máximo possível as barbaridades nazifascistas na Segunda Guerra Mundial com as praticadas nas prisões brasileiras. O aspecto interessante nesse desenho não é só a aproximação entre membros do aparato estatal brasileiro e os regimes nazistas combatidos na Segunda Guerra Mundial, mas a ausência de Getúlio 
Vargas. Poderíamos levantar como hipótese que essa ausência estava relacionada à censura pois foi publicado na vigência do Estado Novo, ainda que em seu ocaso. Todavia, a continuação das denúncias das sevicias mostra que não.

O jornal Hoje de 21 de novembro de 1946 publica desenho sobre a tortura no Estado Novo e passa a utilizar o título específico para a série: "Falta alguém em Nuremberg". A adoção do cabeçalho é posterior a primeira publicação de Nasser e, evidentemente, com a ampla divulgação da revista, remete a ela. De certa maneira o partido absorve a manchete para contar sua versão sobre a tortura, mostrando seus heróis e seus vilões, de acordo com seus interesses do momento.

A manchete afirma "As torturas, sevicias, atrocidades e assassínios da polícia do Estado Novo”. A covardia dos policiais desenhados está expressa em seu maior número, suas armas e no próprio uniforme, todos elementos que criam uma oposição e desproporção com o casal nu que sofre as sevícias, o que aumenta a covardia. A expressão de dor dos torturados se contrapõe aos policiais que são desenhados com sombras sobre os seus olhos, talvez até com óculos, para que não sejam identificados, além de lhes dar um ar sombrio ${ }^{23}$.

Ao incluir uma figura feminina entre as vítimas, a dramaticidade da cena aumenta, reforçada pelo texto acima da figura: "como eram torturadas as mulheres e crianças, esposas e filhos dos comunistas e democratas". Textualmente é citado o sofrimento enfrentado pelos comunistas no período, embora nenhuma referência iconográfica mencione o partido, e a oposição, novamente, ocorre contra a "po-

${ }^{23}$ Comentando o vidro espelhado na arquitetura, Fredric Jamenson faz um paralelo interessante: "é possível querer ressaltar o modo pelo qual a pele de vidro repele a cidade lá fora, uma repulsa para a qual temos analogias nos óculos de sol espelhados, que tornam impossível ao seu interlocutor ver os seus olhos e que, portanto, acabam denotando, não só uma agressividade em relação ao outro, como um poder sobre ele." JAMENSON, Fredric. A virada cultural: reflexões sobre pós-moderno. Rio de Janeiro: Civilização Brasileira, p. 34. 
lícia de Filinto Muller", e não contra o chefe Vargas. Um dos personagens policiais, ao fundo e à sombra, se diferencia do grupo pelo sobretudo e arma na mão, talvez comandando a ação. Nesse sentido, o desenhista poderia induzir o leitor a vê-lo como Filinto Muller.

O mesmo jornal, em 28 de novembro de 1946, mostra um homem amarrado a uma cadeira, seminu e com fogo nos pés. Ele está sem os algozes, mas preso (vemos a porta fechada ao fundo), enquanto a legenda sublinha a queima dos órgãos sexuais: o rosto denota a dor. A queima dos presos era destacada por Nasser como mais um indicativo do sadismo do aparato repressivo:

Os torturadores foram escolhidos a dedo. Havia gente dentro da própria Policia que não aceitava o encargo. Eram chamados "facativos". Somente aos que praticavam a sangue frio o arrancamento de unhas ou a queima da sola do pé com o maçarico era dada a confiança ilimitada dos chefes ${ }^{24}$

Ainda no Hoje, um desenho de 30 de novembro de 1946 acompanha a manchete sobre a menina Marly, de 4 anos, torturada por Filinto Muller. O fato de ser uma menina aumenta o horror da situação. Ademais, um personagem preso à cadeira mostra a chamada "máscara americana", instrumento sufocante que lembra a "folha de flandres" utilizada nos escravos. A legenda afirma que os "antifascistas" presos ficavam nessa posição por horas, o que retomava o contexto da luta na Segunda Guerra Mundial.

O suplício da operária Amália Marques "na sala de torturas de Filinto Muller" foi destaque do Hoje de 11 de dezembro de 1946. Objetos eram enfiados debaixo da mão de uma "antifascista", cujo braço amarrado e o sangue escorrendo aparecem em close. A legenda diz "Um torturador em cada mão introduzia as adelfis nas

24 Ibidem, p. 25. 
mãos dos antifascistas que Felinto Muller prendia”. A caracterização, novamente, remete à Segunda Guerra Mundial e coloca de um lado uma antifascista e de outro Filinto Muller. Nasser também dá nome a essa tortura e cita os "adelfis" no caso do operário Matias dos Santos e de sua companheira Aída:

[...] Ela, Aída, sofreu o martírio dos "adelfis", uns pedacinhos de madeira que era (sic) enfiados por baixo das unhas. Devagarinho, os torturadores iam batendo, aprofundando cada vez mais, até o preso confessar o que fizera e o que não fizera ${ }^{25}$.

Nesse conjunto de desenhos, a ênfase na violência das torturas e incapacidade dos presos se defenderem desloca a ojeriza para o inimigo Filinto Muller. Embora ele não esteja claramente visível, mesmo porque seu rosto não era popular, o texto trata de colocá-lo como autor dessas sevícias, agindo nas sombras. Muller surge como o inimigo ideal: uma vez que teria desertado da Coluna Prestes e se apropriado de recursos da mesma ${ }^{26} \mathrm{e}$, ao focar a autoria das torturas nesse "vilão", o partido poupava Getúlio. Com esse "currículo", a imprensa comunista clama pelo encaminhamento do policial ao Tribunal de Nuremberg, onde eram julgados os criminosos nazistas, aproximando o nazifascismo de lá com os setores de cá.

O grande ausente em todos esses desenhos é Getúlio Vargas, o responsável, em última instância, por essas torturas. Essa construção de sentido visava poupar Vargas, que não é mostrado nos desenhos ou citado no texto, tendo em vista que o partido apoiou o ditador a partir da Conferência da Mantiqueira em 1943, em prol do esforço

25 Ibidem, p.62

26 "Filinto, além de ter fugido covardemente, pendeu para a reação". MORAES, Denis de \& VIANA, Chico. Prestes: lutas e autocríticas, Petrópolis: Vozes, 1982, p. 125. NETO, Lira. Getúlio: do governo provisório à ditadura do Estado Novo (1930 -1945), São Paulo: Cia. das Letras, 2013, p. 136. 
de guerra, mas, ao mesmo tempo, mostrar a crueldade praticada pelos setores fascistas do governo. A iconografia sobre a polícia de Filinto Muller e as suas barbáries alcança esses objetivos, cria uma outra versão para o Estado Novo, dá satisfação e reconhecimento aos militantes comunistas torturados (mas também aos antifascistas e democratas) sem que o chefe de Filinto, Vargas, surgisse como responsável.

No discurso no estádio de São Januário (Rio de Janeiro), em 1945, Prestes falou sobre a liquidação do fascismo:

Não se trata de ódios nem ressentimentos pessoais. Todos nós que sofremos na nossa própria carne e na de nossos seres mais queridos esses anos de perseguições e de cárceres, já provamos, suficientemente, que colocamos os interesses da Pátria, de nosso povo e da Humanidade muito acima de nossas paixões pessoais. ${ }^{27}$

Sem dúvida Prestes aludia também ao exemplo pessoal, pois sua esposa, a judia alemã Olga Benário ${ }^{28}$ foi deportada para a Alemanha nazista onde morreu em um campo de concentração, e ele ainda assim apoiou a continuidade de Vargas; mas o exemplo servia para os demais comunistas torturados no Estado Novo. O que o partido defendia, por meio dos desenhos, era a punição aos fascistas no governo, da mesma maneira que os criminosos nazistas eram punidos em Nuremberg e não a vingança pessoal. Esses desenhos remetem à situação peculiar do partido em relação a Vargas de defender a

27 VINHAS, M. O partidão: a luta por um partido de massas, 1922-1974, São Paulo: HUCITEC, 1982, p. 108.

28 Evidentemente, Nasser também citou o caso de Olga Benário: "quem forneceu essa vítima às câmaras de morte da Alemanha não respondeu, depois, por seus crime, aos juízes de Nuremberg" e dedica um capítulo de seu livro a ela, além de afirmar que Vargas havia mandado matar Prestes.NASSER, David (4. ${ }^{\mathrm{a}}$ ed.). Falta alguém em Nuremberg, Rio de Janeiro: Edições O Cruzeiro, 1966, p. 79. 
continuidade dele em busca da constituinte, ao mesmo tempo em que, ao denunciar a tortura, reconhece e transforma em heróis os militantes comunistas, os democratas, os antifascistas, os operários e suas famílias do período.

A ambiguidade do PCB em relação a Vargas e os constrangimentos oriundos da postura do partido não passaram despercebidos por David Nasser. No livro, o jornalista narra a prisão do importante líder comunista Gregório Bezerra após a insurreição comunista de 1935: "Na sala de carceragem, Gregório encontra seu irmão, e assiste, impotente, os policiais o levarem para a morte. O irmão de Bezerra foi morto a pauladas, depois de cruéis torturas..."29

Em suas memórias, Bezerra reconstrói a morte do irmão, ocorrida em 4 de agosto de 1936 e responsabiliza "Ranulfo Cunha, delegado de Polícia, o bandido Wandenkock Vanderlei, os investigadores João Belarmino e um tal Manuel da Farinha, além de outros". Esses policiais "liquidaram meu irmão abrindo-lhe uma grande brecha no frontal, onde cabia o dorso da mão de um homem" ${ }^{30}$. Depois, "Ranulfo Cunha, junto à turma de bandidos (...) telefonou para o chefe de polícia, Frederico Mendelo [que] deu-se por satisfeito e congratulou-se com seu comparsa" 31

Um nome importante nesse contexto é Etelvino Lins, delegado de polícia e posteriormente político. Gregório Bezerra, comentando sua prisão por conta da insurreição comunista de 1935 cita Lins que apareceu "para ouvir-me, mas portou-se com muita prepotência. Respondi-lhe que ele não era meu senhor, nem eu seu escravo; e que não tinha declarações a fazer-lhe"32.

29 Ibidem, pp. 19-20.

30 BEZERRA, Gregório (3. ${ }^{a}$ ed.). Memórias. $1 .^{a}$ parte, Rio de Janeiro, Editora Civilização Brasileira, 1980, pp. 265-266.

31 Ibidem, pp. 265-266.

32 Ibidem, pp. 249-250. 
Todavia, ao relatar a morte de José Lourenço Bezerra, como vimos, Gregório não cita o envolvimento de Lins nesta morte. Difícil imaginar que se esqueceria de alguém que ele desafiou abertamente. Já Nasser coloca Lins como responsável e dramatiza um reencontro entre Bezerra e o algoz de seu irmão: "Tempos depois, na Assembléia Nacional Constituinte, o Deputado Gregório Bezerra encontrou-se, frente a frente, com o Senador Etelvino, o mesmo que mandara executar seu irmão. Nada aconteceu, porque a ordem era silenciar [grifo nosso]" 33

Talvez Nasser efetivamente tenha errado ao incluir Etelvino Lins como responsável pela morte de Jose Loureço Bezzera, mas o polêmico jornalista atacou um ponto central ao ressaltar que "a ordem era silenciar" nessa fase de legalidade do PCB em que o passado precisava ser lido de acordo com os interesses do partido. A partir da ilegalidade em 1947, a iconografia do partido sobre Vargas e o Estado Novo muda completamente.

Um desenho de Quintino Campofiorito publicado no Voz Operária de 2 de setembro de 1950 mostra um Vargas caminhando com a escolta de três monstros: o Tribunal de Segurança Nacional, o Departamento de Imprensa e Propaganda e a Polícia Especial. A legenda da imagem afirma: "Assim foi a tirania do sanguinário Getúlio Vargas: polícia contra a classe operária e o povo e a mais feroz justiça de classe contra os que lutavam pela libertação nacional e amordaçamento da imprensa livre". Vargas agora aparece, acompanhado pelo séquito de monstros, o seu passado o condena.

O jornal Hoje de 4 de agosto de 1950 publica um quadrinho em que um Vargas minúsculo e fisicamente decadente fala a um microfone. Em cima de uma cadeira para chegar a um microfone, que se afasta por repulsa ao ex-presidente (seu discurso/hálito está

33 NASSER, David (4. ${ }^{a}$ ed.). Falta alguém em Nuremberg, Rio de Janeiro: Edições O Cruzeiro, pp. 19-20. 
podre, mostra o passado e a decadência), o líder diz que "Durante anos o povo formou comigo". No quadrinho seguinte, sob a legenda "os que realmente formaram com ele", Vargas aparece novamente com o TSN, DIP e Polícia especial. O passado voltava para denegrir Vargas, o que o PCB evitou no período da legalidade na série "Falta alguém em Nuremberg". Novos objetivos políticos, novos olhares sobre o passado. 